\title{
Economic Analysis of New Energy-saving Maintenance Technology for Airport Pavement Concrete
}

\author{
MA Daoxun ${ }^{1,2, a}$, LIU Yan ${ }^{1,2, b}$, SU Xin ${ }^{1,2}$, LAI Yong ${ }^{1,2, c}$, WANG Peng ${ }^{1,2}$ \\ ${ }^{1}$ China Airport Construction Group Corporation, Beijing, 100101, China \\ ${ }^{2}$ Beijing Super-Creative Technology Co., LTD, Beijing, 100621, China \\ adaoxunma@126.com, ${ }^{b}$ tjdoc@tom.com, ${ }^{\mathrm{C}} \mathrm{Izg} 2076 @ 163 . c o m$
}

\begin{abstract}
Keywords: Airport pavement concrete, Curing membrane maintenance, Economic analysis
Abstract. Maintenance is an important means to ensure the quality of airport pavement concrete and an indispensable key link in the construction process of the airport pavement. This article through engineering example of airport pavement construction contrasts the economy of most commonly used geotextile maintenance with that of more advanced curing membrane maintenance technology throughout the conservation period. The results show that the labor and water cost of curing membrane maintaining airport pavement concrete comparing with geotextile maintaining airport pavement concrete are greatly reduced, and the total cost of maintenance saves about $1 / 3$, which has a very significant economic value.
\end{abstract}

\section{Introduction}

Concrete is a kind of hydraulic material, which reason why it is capable of gradually condensing and hardening after pouring is mainly due to the result of cement hydration. However, hydration requires proper temperature and humidity conditions, therefore, in order to ensure concrete being suitable hardening conditions so that its strength continues to grow, it is indispensable for concrete to be maintained. After concrete being poured, if the climate is hot and dry, the moisture in the concrete will evaporate too quickly without timely maintenance, resulting in the dehydration and cement particles having formed gel fail to be fully hydrated and transformed into a stable crystal, thereby there will be flake or powdery falling off on the concrete surface. In addition, when the concrete has not yet had enough strength, premature evaporation of water will touch off greater shrinkage deformation and shrinkage cracks ${ }^{[1]}$. Hence, the maintenance of initial stage after concrete be poured is of pretty importance.

Conventional concrete maintenance methods include natural maintenance, atmospheric steam maintenance, high-temperature and high-pressure maintenance. At present, for airport pavement concrete it is dominated by natural maintenance. Natural maintenance methods comprise watering conservation, plastic film conservation (including curing membrane ${ }^{[2]}$ ) and so on. Covered watering conservation is based on outside temperature, within $3 \sim 12 \mathrm{~h}$ after completion of concrete pouring with straw curtains, reeds, sacks, sawdust, wet soil and wet sand and other appropriate materials it is covered for concrete, and which needs often water to keep moist; Plastic film conservation is based on water absorption and water conservation film for the cover, or spraying the plastic solution on the concrete surface until the solution being evaporated resulting in the concrete surface forming a layer of plastic film which will enable between the concrete and the air to be isolated and moisture no longer to be evaporated, so that the cement is hardened by the water in the concrete accomplishing its hydration ${ }^{[3-7]}$.

The main purpose of the thesis is to evaluate the economical efficiency of curing membrane maintenance and traditional geotextile maintenance through the concrete curing contrast test at the actual construction site, to verify the practicability of maintaining pavement concrete with curing membrane in order to improve the quality of maintenance, to furnish the reference and engineering basis for large area popularization of curing membrane maintenance method for airport pavement concrete $^{[8-10]}$. 


\section{Experiments}

Test scheme. In this paper, for the conventional geotextile maintenance, it is about to water three times a day, covering concrete with geotextile to $14 \mathrm{~d}$ age; curing membrane consists of a mask and a base film, the mask possesses the properties of tensile strength and water retention, the base film as ultra-thin plastic film is typical of water permeability on which there is full of granular water absorbent polymer material. The film single roll width of curing membrane is $2.8 \mathrm{~m} \times 300 \mathrm{~m}$, covering airport pavement concrete with curing membrane to $14 \mathrm{~d}$ age. As showed in Fig.1, it's the flow chart of curing membrane.

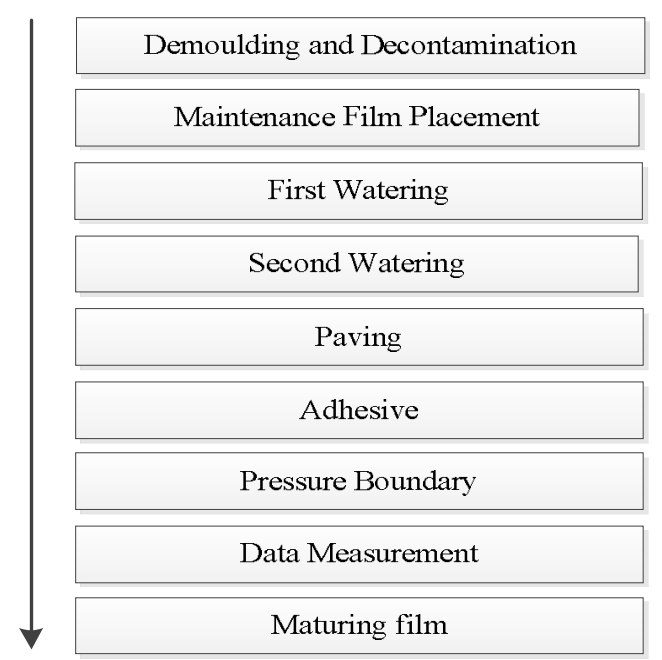

Fig.1 Flow chart of curing membrane

Maintenance main configuration. Mechanical equipment in maintenance test and maintenance staff and duty are presented at Table 1 and Table 2, respectively.

Table 1 mechanical equipment in maintenance test

\begin{tabular}{ccc}
\hline \multicolumn{2}{c}{ Mechanical name } & Allocation \\
Watering car & One car \\
Self-made simple paving tool & two suites \\
Leveling tool & two items \\
\hline \multicolumn{2}{c}{ Table 2 maintenance staff and duty } \\
\hline Maintenance type & number & duty \\
\hline curing membrane & Four & Sprinkling, paving, pressing \\
geotextile & Five & Laying geotextiles, watering \\
\hline
\end{tabular}

Engineering field test. The test site is located in the Tianjin Binhai International Airport Phase II expansion project, which construction is in summer. The test section covers an area of $40,000 \mathrm{~m}^{2}$ (the curing membrane of $20,000 \mathrm{~m}^{2}$, the geotextile of $20,000 \mathrm{~m}^{2}$ ). Concrete is supplied by on-site three-way concrete mixing plant.

In the Tianjin Binhai International Airport Phase II expansion project it is carried out for airport pavement concrete conservation test by geotextiles and curing membrane, the specific effect is shown in Fig. 2. 


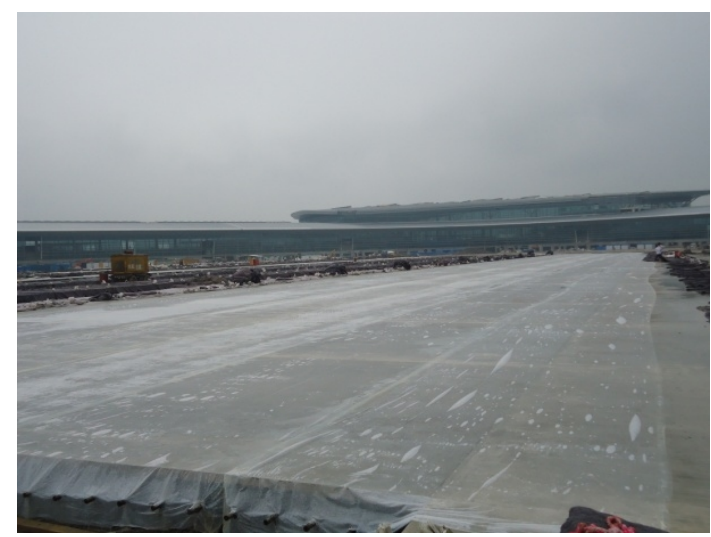

(a) Curing membrane Field Conservation Testing

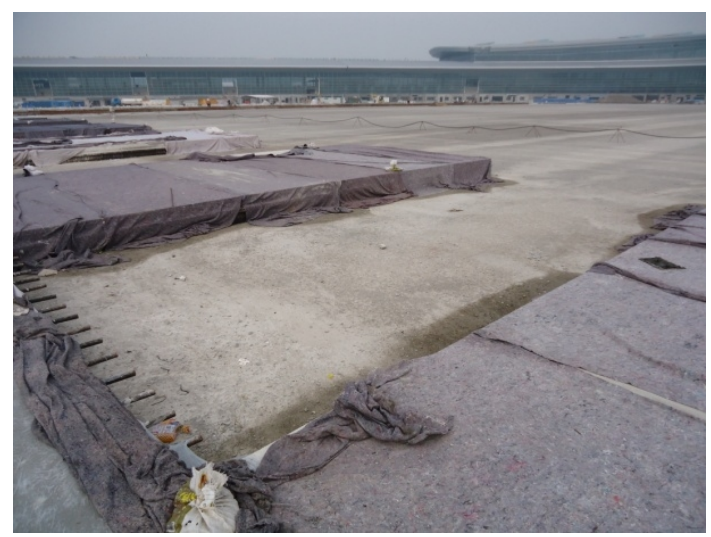

(b) Geotextile Field Conservation Testing

Fig.2 Tianjin Binhai International Airport Phase II expansion project maintenance test site

\section{Economic Analysis}

Maintaining the two kinds of $20000 \mathrm{~m}^{2}$ of airport pavement concrete as the basis for calculation, the main consideration is in the following aspects: water costs, geotextile (or curing membrane) costs, labor costs.

Curing Membrane Maintenance. Water costs. By curing membrane maintaining pavement concrete, in theory, it is only necessary to pour enough water on the initial paving, sometimes according to the actual project, it requires a certain degree of replenishment, so considering that the maximum water consumption is 0.002 tons per square meter and currently the industrial water is 7.85 CNY per ton of water, so:

$$
\begin{aligned}
C_{\mathrm{w} 1} & =R_{\mathrm{w}} \times A_{\mathrm{m}} \times C_{t \mathrm{p}} \\
& =0.002 \times 20,000 \times 7.85 \\
& =314 C N Y .
\end{aligned}
$$

Where in the Eq. 1, $C_{\mathrm{w} 1}$ : water costs,

$R_{\mathrm{w}}$ : water required per square metre,

$A_{\mathrm{m}}$ : area of curing membrane maintaining pavement concrete,

$C_{t \mathrm{p}}$ : water price per ton.

Curing membrane costs. The price of curing membrane is $2.00 \mathrm{CNY}$ per square meter, and the number of available use is 1 times, so:

$$
\begin{aligned}
C_{\mathrm{m} 1} & =C_{\mathrm{mp}} \times A_{\mathrm{m}} \times\left(1 / T_{\mathrm{am}}\right) \\
& =2 \times 20,000 \times(1 / 1) \\
& =40,000 C N Y .
\end{aligned}
$$

Where in the Eq. 2, $C_{\mathrm{m} 1}$ : curing membrane costs,

$C_{\text {mp: }}$ : price of curing membrane per square metre,

$A_{\mathrm{m}}$ : area of curing membrane maintaining pavement concrete,

$T_{\mathrm{am}}$ : available using times of curing membrane.

Worker labor costs. Although the number of workers requires for the curing membrane being laid is 4 persons (shown in Table 2.2), the time used for laying is short, and the daily maintenance needs only 2 workers because of no needing to water in the later period. Therefore, according to the actual project situation, From laying curing membrane to $14 \mathrm{~d}$ age it can be calculated in accordance with the workload of three people which monthly salary is about 5,000 CNY, the maintenance process is 14 days meaning that workers need to work on this item for half a month, then:

$$
C_{11}=N_{\mathrm{wk}} \times S_{\mathrm{wk}} \times M_{\mathrm{a}}
$$




$$
\begin{aligned}
& =3 \times 5,000 \times 0.5 \\
& =7,500 C N Y
\end{aligned}
$$

Where in the Eq. 3, $C_{11}$ : worker labor costs,

$$
\begin{aligned}
& N_{\mathrm{wk}}: \text { number of workers, } \\
& S_{\mathrm{wk}}: \text { monthly salary per worker, } \\
& M_{\mathrm{a}}: \text { maintenance age. }
\end{aligned}
$$

Total costs. As the total cost of curing membrane maintaining concrete includes the cost of water, the cost of geotextiles and the labor cost of workers, then:

$$
\begin{aligned}
C_{\mathrm{T} 1} & =C_{\mathrm{w} 1}+C_{\mathrm{m} 1}+C_{11} \\
& =314+40,000+7,500 \\
& =47,814 C N Y
\end{aligned}
$$

Where in the Eq. $4, C_{\mathrm{T} 1}$ : total costs,

$$
\begin{aligned}
& C_{\mathrm{w} 1} \text { : water costs, } \\
& C_{\mathrm{m} 1} \text { : curing membrane costs, } \\
& C_{11} \text { : worker labor costs. }
\end{aligned}
$$

Geotextile Maintenance. Water costs. According to the actual project, for geotextile maintenance in the entire process the water required per square metre concrete is of 0.2 tons, currently the water for construction purpose is $7.85 \mathrm{CNY}$ per ton, then:

$$
\begin{aligned}
C_{\mathrm{w} 2} & =R_{\mathrm{w}} \times A_{\mathrm{m}} \times C_{t \mathrm{p}} \\
& =0.2 \times 20,000 \times 7.85 \\
& =31,400 C N Y
\end{aligned}
$$

Where in the Eq. $5, C_{\mathrm{w} 2}$ : water costs,
$R_{\mathrm{w}}$ : water required per square metre,
$A_{\mathrm{m}}$ : area of curing membrane maintaining pavement concrete,
$C_{t \mathrm{p}}$ : water price per ton.

Curing membrane costs. The price of geotextile is of 5.00 CNY per square meter, the number of available use is 4 times, then:

$$
\begin{aligned}
C_{\mathrm{m} 2} & =C_{\mathrm{gp}} \times A_{\mathrm{g}} \times\left(1 / T_{\mathrm{ag}}\right) \\
& =5 \times 20,000 \times(1 / 4) \\
& =25000 C N Y
\end{aligned}
$$

Where in the Eq. 6, $C_{\mathrm{m} 2}$ : geotextile costs,

$C_{\mathrm{gp}}$ : price of geotextile per square metre,

$A_{\mathrm{g}}$ : area of geotextile maintaining pavement concrete,

$T_{\mathrm{ag}}$ : available using times of geotextile.

Worker labor costs. The number of workers whose task includes laying geotextiles, watering and routine maintenance is 5, and workers' monthly salary is of 5,000 CNY and the maintenance process is of 14 days, that is, workers need to invest time on this item for half a month:

$$
\begin{aligned}
C_{12} & =N_{\mathrm{wk}} \times S_{\mathrm{wk}} \times M_{\mathrm{a}} \\
& =5 \times 5,000 \times 0.5 \\
& =12,500 C N Y
\end{aligned}
$$

Where in the Eq. 7, $C_{12}$ : worker labor costs,

$N_{\text {wk }}$ : number of workers,

$S_{\text {wk }}$ : monthly salary per worker,

$M_{\mathrm{a}}$ : maintenance age. 
Total costs. Since the total cost of geotextile maintenance includes the cost of water, the cost of geotextiles and the labor costs of workers, then:

$$
\begin{aligned}
C_{\mathrm{T} 2} & =C_{\mathrm{w} 2}+C_{\mathrm{m} 2}+C_{12} \\
& =31,400+25,000+12,500 \\
& =68,900 C N Y
\end{aligned}
$$

Where in the Eq. $8, C_{\mathrm{T} 2}$ : total costs,

$C_{\mathrm{w} 2}$ : water costs,

$C_{\mathrm{m} 2}:$ geotextile costs,

$C_{12}$ : worker labor costs.

Comparison of two kinds of maintenance methods. The main cost comparison between geotextile maintenance and curing membrane maintenance is shown in Figure 3.1. Relative to the geotextile maintenance, the water costs of curing membrane maintenance is saved $99 \%$, worker labor costs is saved about $40 \%$.

For curing membrane maintenance /geotextile maintenance:

A. Water costs ratio $=C_{\mathrm{w} 1} / C_{\mathrm{w} 2}=314 / 31,400=1 \%$

B. Material costs ratio $=C_{\mathrm{m} 1} / C_{\mathrm{m} 2}=40,000 / 25,000=160 \%$

C. Worker labor costs ratio $=C_{11} / C_{12}=7,500 / 12,500=60 \%$

D. Total costs ratio $=C_{\mathrm{T} 1} / C_{\mathrm{T} 2}=47,814 / 68,900=69 \%$

Hence, the curing membrane maintenance significantly reduces the amount of water requirements while saving labor costs, furthermore, although the maintenance material itself is a little higher in terms of price, the total cost of maintaining airport pavement concrete with the curing membrane is about $1 / 3$ less than with the geotextile. So maintaining with curing membrane has a pretty significant promotion and application potential and economic value.

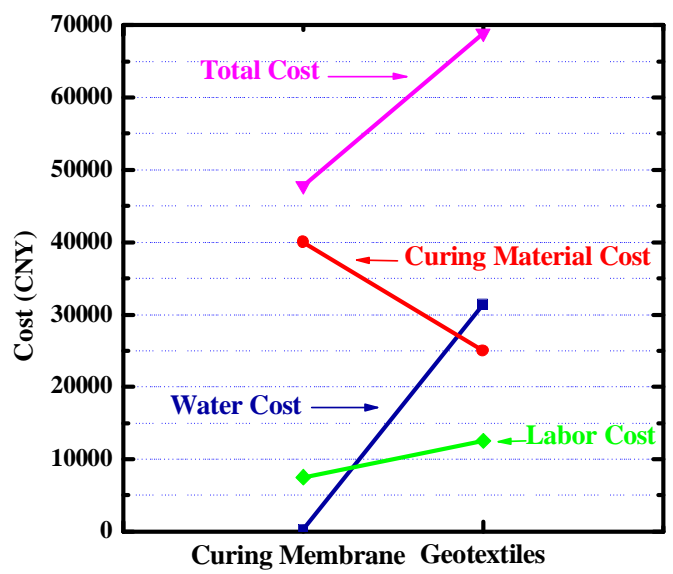

Figure 3.1 Main cost comparison of two maintenance methods

\section{Conclusions}

The economic analysis of two maintenance methods consisting of curing membrane maintenance and geotextile maintenance is carried out in this paper.

Compared with the geotextile maintenance:

(1) The water costs of curing membrane maintenance is saved $99 \%$, worker labor costs is saved about $40 \%$, that is, the curing membrane maintenance significantly reduces the amount of water requirements while saving labor costs.

(2) The total cost of maintaining airport pavement concrete with the curing membrane is about $1 / 3$ less than with the geotextile. 
(3) The curing membrane has a pretty significant promotion potential and economic value in the practical engineering application.

\section{Acknowledgements}

This work is financially supported by the Major Projects of Civil Aviation Administration (Grant Nos.MHRD20130109), Civil Aviation Science and Technology Project (Grant Nos.MHRD20150225) and Capital Airport Holding Co. Science and Technology Project (Research on the key technology of new materials about high durability and high crack resistance airport pavement).

\section{References}

[1] Romualdi J P, Batson G B, Mechanics of crack arrest in concrete. Journal of the Engineering Mechanics Division, 2015, 3(89): 147 168

[2] JG Standards. Curing sheet for concrete with water saving and moisture retention (JB/T 188-2010). Ministry of housing and urban and rural construction in P.R., China, 2010

[3] Ma Hui, Chen Xuefei,etc. preparation of water saving and moisture retention film for concrete curing. Journal of Textile Research, 2013, 34(5):82 87

[4] He Xuefeng. Discussion on the application of water saving and moisturizing maintenance membrane in highway bridge and culvert construction. Science \& Technology Information: 2011(31): 206 211

[5] Chen huichao, Luo Liping, Luo Wanwan. Construction method of water saving and moisturizing maintenance membrane. Technology Trend, 37(2013):1453 1457

[6] Wang Shoukui. Application of water saving and moisturizing curing membrane in South to North Water Transfer Project. Water Conservancy Planning and Design, 1(2010):57 61

[7] Li Dongsheng. Construction technology of water saving moisturizing maintenance membrane and geogrid composite water stable structure. SHANXI ARCHITECTURE, 2015, 41(24):134 139

[8] Gao Jiuping, Li Manrong Cao Ruwei. Performance test of water saving and moisturizing maintenance film on Cement Concrete Pavement. Hunan Communication Science and Technology, 2006, 32(2):66 69

[9] Huang Jie, Yang Xiaohong. Research and development of new water saving and moisturizing curing membrane for concrete. China Highway, 18(2002):847 851

[10]Li Hang. Application of water-saving wet curing membrane in Henzhao highway. Hunan Communication Science and Technology, 2007, 33(2): 36 41 